\title{
Enhanced colon cancer chemoprevention of curcumin by nanoencapsulation with whey protein
}

Guddadarangavvanahally K Jayaprakasha*, Kotamballi N Chidambara Murthy ${ }^{\mathrm{a}}$, and

Bhimanagouda S Patil*

Vegetable and Fruit Improvement Center, Department of Horticultural Sciences

Texas A\&M University, College Station, TX 77845-2119

${ }^{a}$ Current affiliation: Central Research Laboratory, MS Ramaiah Medical College \& Hospitals MSR Nagar, MSRIT Post, Bangalore 560 054, India

*Author for correspondence

Phone: +1 979-458-8090; Fax: +1 979-862-4522; E mail: b-patil@tamu.edu; gkjp@tamu.edu 


\section{ABSTRACT}

To improve bioavailability and enhance colon cancer prevention ability of curcumin, whey protein was used to nanoencapsulate at three different ratios such as 70:30, 50:50 and 35:65 for the first time. The drug loading, entrapment efficiency and structural changes of curcumin was confirmed by quantitative NMR spectroscopy. The nanoparticles prepared using the three ratios had an average diameters of $236.5 \pm 8.8,212 \pm 3.4$, and $187 \pm 11.4 \mathrm{~nm}$, as well as zeta $(\zeta)$ potentials of $-13.1,-9.26$, and $-4.63 \mathrm{mV}$, respectively, at $\mathrm{pH} 7.0$. The cytotoxicity assay was performed for human colon and prostate cancer (SW480 and LNCap) by MTT assay and results showed significantly higher cytotoxicity of nanoencapsulated curcumin (NEC) (equivalent to 30.91, 20.70 and $16.86 \mu \mathrm{M}$ of NEC-1, 2 and 3 respectively), as compared to plain curcumin at $50 \mu \mathrm{M}$ after $72 \mathrm{~h}$ of treatment. Cytotoxicity was also confirmed by microscopy of treated cells stained with acridine orange and propidium iodide. The cells treated with $50 \mu \mathrm{M}$ of curcumin, $30.91 \mu \mathrm{M}$ (NEC-1), 20.70 $\mu \mathrm{M}$ (NEC-2) and $16.86 \mu \mathrm{M}$ (NEC-3) showed enhanced activation of p53 and elevated bax/Bcl2 expression (NEC-3), increased cytochrome-c in cytosol (NEC-2) confirming the enhanced cytotoxicity. To confirm the increased bioavailability, the intracellular curcumin was measured using fluorescence intensity. The fluorescent signal for intracellular curcumin was increased by 12,30 , and $21 \%$ for NEC-1, NEC-2, and NEC-3 respectively as compared to plain curcumin at $4 \mathrm{~h}$. Based on these results, we conclude that nanoencapsulated curcumin with whey protein will have potential to be considered for clinical applications for future studies.

Keywords: Curcuma longa, nanoencapsulation, whey protein, zeta potential, colon cancer Chemical compounds studied in this article: Curcumin (PubChem CID 969516) 


\section{Introduction}

In spite of promising health beneficial properties of curcumin in various invitro and invivo models, the pharmacokinetic and bioavailability studies indicates the poor absorption and rapid elimination from the body (Shehzad et al., 2010). Therefore, a number of strategies have been attempted to enhance the bioavailability of curcumin, including the use of therapeutic adjuvants, liposomal curcumin, curcumin nanoparticles, curcumin-phospholipid complexes, and structural analogues of curcumin (Yallapu et al., 2015). Piperine enhanced the bioavailability of curcumin up to 20-fold by acting on the major metabolic enzyme glucuronidinase, which is responsible for rapid degradation of curcumin in liver and intestinal tissue (Shoba et al., 1998). More recently curcumin- $\beta$-cyclodextrin / cellulose nanocrystals tested for the inhibition of colorectal and prostate cancer cell lines. The curcumin nanocrystals exhibited $\mathrm{IC}_{50}$ less than curcumin (Ndong et al., 2016). However, the release rate seems to be very poor. The use of curcumin-phospholipid combination resulted in significant elevation of bioavailability compared to plain curcumin in plasma at different time points (Marczylo et al., 2007). Currently more than thousands of different nanoparticles are known but there are no well-defined guidelines to evaluate their potential toxicity and safety (Elzoghby et al., 2012). It is important to consider the safety of the polymeric material and other excipients used in alternative delivery system.

Protein serves as the natural counterpart to synthetic polymers for the development of nanoparticles due to their characteristic properties such as biodegradability and added nutritional value. Thus proteins were considered as generally regarded as safe drug delivery devices. Due to this reason, protein encapsulated nanoparticles were widely prepared for commercial applications (Elzoghby et al., 2012). Based on the existing literature, we hypothesized the use of whey protein as safe alternatives to synthetic polymer, which may improve both pharmacokinetic 
and dynamic properties of curcumin. The current study investigates the development of formulation process for the nanoencapsulation of curcumin with whey protein at different ratios to obtain stable complexes. These nanoencapsulated samples were characterized for entrapment, size, PDI, zeta potential, in vitro release, and morphological behavior, along with their cytotoxicity effect on human colon and prostate cancer cells. Novelty of the study lies in utilizing natural ingredient for encapsulation and formulation of nanosized molecules for enhancing health beneficial properties of curcumin.

\section{Materials and methods}

\subsection{Chemicals}

Whey protein (gold standard) was purchased from a local supermarket (College Station, TX, USA). All analytical and high-performance liquid chromatography (HPLC) grade solvents and molecular biology grade dimethyl sulfoxide (DMSO) were obtained from Sigma (St. Louis, MO, USA). Nanopure water (NANOpure, Barnstead, Dubuque, IA, USA) was used for liquid chromatography. Pure curcumin was isolated and identified in our laboratory according to our recently published method (Jayaprakasha et al., 2013). Dulbecco's Modified Eagle Medium and chemicals used for cell culture were purchased from Hyclone (Logan, UT, USA); penicillin, streptomycin mixture and trypsin ethylene diamine tetra acetic acid were purchased from Mediatech Inc., (Herndon, VA, USA). Protein detection bicinchoninic acid kit, all primary and secondary antibodies used in the study were purchased from Santa Cruz Biotechnology (Santa Cruz, CA, USA) and Cell Signaling Technologies (Danvers, MA, USA). The western blot 
images were captured using a LAS4000 mini imaging system (Fuji medical system, Woodbridge, CT, USA) under chemiluminescence mode.

\subsection{Nanoencapsulation of curcumin by desolvation method}

A $10 \%(\mathrm{w} / \mathrm{v})$ solution of whey protein in nanopure water and $10 \%$ curcumin in acetone was prepared by stirring on a $500 \mathrm{rpm}$ magnetic stirrer at $27^{\circ} \mathrm{C}$ for $2 \mathrm{~h}$ and $30 \mathrm{~min}$, respectively. Nanoencapsulated curcumin (NEC) was prepared by a desolvation method (Langer et al., 2003) with three different ratios of curcumin to whey protein such as 70:30 (NEC-1), 50:50 (NEC-2), and 35:65 (NEC-3). For instance, NEC-1 was prepared by slowly mixing dropwise $140 \mathrm{mg}$ of curcumin in $1.5 \mathrm{ml}$ of acetone to $2.5 \mathrm{ml}$ aqueous whey protein $(60 \mathrm{mg})$ under constant stirring on a magnetic stirrer at $500 \mathrm{rpm}$. The mixture was further kept on the magnetic stirrer at $25^{\circ} \mathrm{C}$ for 8

$\mathrm{h}$ followed by homogenization at 5,000 rpm for $1 \mathrm{~min}$. The resulting emulsion was centrifuged at $7826 \mathrm{x} g$ for $20 \mathrm{~min}$ at $4^{\circ} \mathrm{C}$ to remove the unbound curcumin. The reside was lyophilized and stored at $-80^{\circ} \mathrm{C}$ until further use. This preparation was named as nanoencapsulated curcumin 1 (NEC-1). In similar fashion, the other two formulations (50:50 and 35:65) were prepared by drop wise mixing of $1.5 \mathrm{ml}$ of acetone containing curcumin (100 and $70 \mathrm{mg}$ ) to $2.5 \mathrm{ml}$ of whey protein (100 and $130 \mathrm{mg}$ ) separately and named as NEC-2 and NEC-3, respectively. The remaining steps were followed as mentioned above to obtain dried powder.

\subsection{Particle size, polydispersity index (PDI), and zeta potential}

The particle size, PDI, and zeta potential of encapsulated curcumin were measured with a Zetasizer Nano ZS (Malvern Instruments, Westborough, MA) using phosphate-buffered saline (PBS) buffer ( $\mathrm{pH} \mathrm{7.4)} \mathrm{as} \mathrm{dispersion} \mathrm{medium} \mathrm{at} 25^{\circ} \mathrm{C}$. Two $\mathrm{mg}$ of sample was mixed with $2 \mathrm{ml}$ of 
buffer solution and vortexed for 3 min; this sample was then used for particle size and zeta potential measurement. The sizes of the curcumin-loaded whey protein formulations were measured using dynamic light scattering (DLS) particle size. Sample aliquots in PBS buffer were loaded into disposable capillary cells for reading by the Zetasizer, which measures the diffusion of particles moving under Brownian motion, and converts this to size and a size distribution using the Stokes-Einstein relationship. The measured particle size was calculated by Zetasizer software (version 7.02) and includes inputs of the particle reflective index and the buffer system used. The dispersion $\mathrm{pH}$ was 7.0 for the control and the sample containing curcumin. An average of 10 measurements was used to calculate the size. PDI gives an indication of the particle size distribution, which was calculated as the weight average molecular weight divided by the number average molecular weight. The zeta potential of the particles was measured with the Zetasizer. The $\zeta$-potential was calculated from the electrophoretic mobility based on the Helmholtz-Smoluchowski formula. All calculations were carried out with the Zetasizer software.

\subsection{Drug-loading and entrapment efficiency of curcumin}

The drug loading (DL) and entrapment efficiency (EE) of curcumin were analyzed with a quantitative proton NMR spectrometer (JEOL USA, Inc., Peabody, MA, USA) operating at 400 MHz and equipped with a 5-mm multinuclear inverse probe head and NM-ASC24 sample changer (Jayaprakasha and Patil, 2016). A known quantity (2-4 mg) of nanoencapsulated sample was dissolved in $525 \mu \mathrm{L}$ DMSO- $\mathrm{d}_{6}$, transferred to a 5-mm NMR tube, and spectra were recorded at $25^{\circ} \mathrm{C}$. An external coaxial glass tube (OD 2mm) (Shigemi Inc, Allison Park, PA, USA) containing $65 \mu 10.012 \% 3$-(trimethylsilyl) propionic-(2, 2, 3, 3- $\left.\mathrm{d}_{4}\right)$ acid sodium salt (TSP- $\left.\mathrm{d}_{4}\right)$ (Cambridge Isotope Laboratories, Inc., Tewksbury, MA, USA) in $\mathrm{D}_{2} \mathrm{O}$ was inserted into the NMR sample tube as a quantitative reference. The TSP- $\mathrm{d}_{4}$ concentration in the tube was pre- 
calibrated using a separate standard solution. All spectra were acquired with a 15 ppm sweep width, 12 s relaxation delay, four prescans and 32 transients. Further, spectra were zero filled to $131 \mathrm{k}$ data points and data were processed using Delta software version 4.3.6. The DL and EE of NEC-1, NEC-2, and NEC-3 were calculated according to the formula:

$\mathrm{DL}=\frac{\text { drug }}{\text { polymer }+ \text { drug }} \quad$ and $\quad \mathrm{EE}=\frac{\text { experimental drug loading }}{\text { theoretical drug loading }} \times 100$ According NMR results, the actual curcumin present in stock solution of $50 \mu \mathrm{M}$ of NEC-1, NEC-2 and NEC-3 was found to be $30.91,20.70$ and $16.86 \mu \mathrm{M}$ respectively.

\subsection{Field emission scanning electron microscopy (FE-SEM)}

The shape and surface morphology were determined with an ultra-high-resolution field emission JSM-7500F scanning electron microscope (JEOL-USA, Peabody, MA, USA) equipped with a high brightness conical field emission gun and a low aberration conical objective lens. For SEM, a thin film of aqueous well dispersed nanoemulsion was applied to double-stick tape over an aluminum stub and vacuum dried to get a uniform layer of particles. These particles were coated with platinum-palladium using a sputter gold coater. Samples were dried under vacuum and the morphology of the nanoparticles was observed at $15 \mathrm{kV}$.

\subsection{In vitro release kinetics of curcumin}

The in vitro release kinetics of curcumin was measured using PBS (10 mM, pH 7.4) buffer and the release rate was determined by HPLC (Jayaprakasha et al., 2013). A known quantity of encapsulated sample $(5 \mathrm{mg}$ ) was dispersed in $10 \mathrm{ml}$ of PBS buffer and kept on a shaker (at $100 \mathrm{rpm}$ ) for $48 \mathrm{~h}$ at $25^{\circ} \mathrm{C}$. Every $12 \mathrm{~h}, 500 \mu \mathrm{l}$ of sample was taken and filtered through a $0.45 \mu \mathrm{m}$ filter to remove undissolved curcumin. Two hundred $\mu \mathrm{l}$ of acetone was added and the sample was injected into the HPLC (Agilent HPLC 1200 series, Foster City, CA, USA) 
consisting of a degasser, quaternary pump, autosampler, column oven, and photodiode array detector. Elution of curcumin was carried out with gradient mobile phases of (A) $3 \mathrm{mM}$ phosphoric acid in water and (B) acetonitrile with a flow rate of $0.7 \mathrm{ml} / \mathrm{min}$ at $30^{\circ} \mathrm{C}$ using a Gemini $\mathrm{C}_{18}$ (Phenomenex, Torrance, $\mathrm{CA}$ ) column. Curcumin was determined using the gradient: $75 \%$ to $45 \%$ A from 0 to $3 \mathrm{~min}, 45 \%$ to $20 \%$ in $3-8 \mathrm{~min}, 20-10 \%$ in $8-12 \mathrm{~min}$, and $10-75 \%$ in 12-15 min and maintained for isocratic run for $2 \mathrm{~min}$ to equilibrate the HPLC column. The levels of curcumin were quantified by calibration graph and dilution factor. Data were processed using the CHEMSTATION software (Agilent, Foster City, CA, USA).

\subsection{Cell culture, maintenance and samples preparation}

The colon cancer cell line (SW480) and prostate cancer (LNCaP) cells were obtained from ATCC (Manassas, VA, USA). Pancreatic cancer cell lines (Panc-28) were received from Dr. Paul Chiao, Department of Molecular and Cellular Oncology, The University of Texas, M. D. Anderson Cancer Center, Houston, TX. The SW480 and Panc-28 cells were cultured in Dulbecco's modified eagle's medium (DMEM) using 10\% fetal bovine serum (FBS) with 100 units each of penicillin and streptomycin. LNCaP cells were cells were cultured in RPMI-1640 media containing 10\% FBS and 100 units each of penicillin and streptomycin. All cell culture experiments were conducted during 6-12 passage numbers of cells. Cells were cultured and maintained during experiments in sterile $75 \mathrm{~cm}^{2}$ falcon flasks at $37^{\circ} \mathrm{C}$ under $5 \%$ carbon dioxide and $85 \pm 5 \%$ relative humidity. After $70 \%$ confluence, cells were used for the experiments. Different concentrations (1-50 $\mu \mathrm{M})$ of nanoencapsulated samples were used for all biological assays. The actual curcumin present in stock solution of $50 \mu \mathrm{M}$ NEC-1, NEC-2 and NEC-3 was equivalent to $30.91,20.70$ and $16.86 \mu \mathrm{M}$, respectively and rest of the concentrations NEC samples were presented in Table S1. 


\subsection{MTT assay}

The viability of SW480, LNCaP and Panc-28 cells after treatment with plain and nanoencapsulated curcumin were measured using the MTT (3-(4, 5-dimethylthiazole-2-yl)-2, 5diphenyl tetrazolium bromide) assay. Approximately, $10 \times 10^{3}$ cells/well were grown for $24 \mathrm{~h}$ in 96 well plate to attained $70 \%$ confluence. Then, media was replaced with fresh media containing different concentrations (1-50 $\mu \mathrm{M})$ of plain curcumin, NEC and whey protein. After 24,48 , and $72 \mathrm{~h}$ of incubation, MTT solution was added and incubated for $2 \mathrm{~h}$ in incubator and the formazan was dissolved in DMSO and viability of cells was calculated based on the intensity of formazan according to our previously published method (Murthy et al., 2011).

\subsection{Microscopy of cells stained with $A O$ and PI}

Approximately, $1 \times 10^{5} \mathrm{SW} 480$ cells/well were grown in borosilicate sterile twochambered coverglasses (Lab-Tek brand, Nalge Nunc International, NY, USA) for 24 h, which were pre-incubated with fetal bovine serum for $4 \mathrm{~h}$. The cells were treated with $50 \mu \mathrm{M}$ plain curcumin, NEC samples and equivalent amount of whey protein for $24 \mathrm{~h}$ (control). Later, cells were treated with $5 \mu \mathrm{M}$ acridine orange (AO) and propidium iodide (PI), and incubated at $37^{\circ} \mathrm{C}$

for $15 \mathrm{~min}$. The supernatant and excess dye was removed after $10 \mathrm{~min}$ and washed twice with DMEM (without phenol red) and fluorescence images of stained cells were captured using a Zeiss digital imaging workstation (Murthy et al., 2012).

\subsection{Western blot}

SW480 cells treated with $50 \mu \mathrm{M}$ of plain curcumin and NEC samples (equivalent to 30.91, 20.70 and 16.86 $\mu \mathrm{M}$ for NEC-1, 2 and 3, respectively) for $24 \mathrm{~h}$ were washed in PBS, lysed 
in radio immunoprecipitation assay buffer containing protease inhibitor cocktail for 30 min on ice, and centrifuged at $7826 \times \mathrm{g}$ for $15 \mathrm{~min}\left(4^{\circ} \mathrm{C}\right)$. The protein content of the supernatant was measured using a bovine serum albumin (BSA) standard curve. Samples equivalent to $50 \mu \mathrm{g}$ of protein were denatured and resolved on $12 \%$ SDS-PAGE using a Mini-PROTEAN Tetra Electrophoresis System (Bio-Rad Laboratories, Hercules, CA, USA). Western blotting was performed as per our previously described protocol using the appropriate primary and secondary antibodies (Patil et al., 2009).

\subsection{Curcumin absorption using fluorescence imaging}

Based on the fluorescent nature of curcumin, the content of absorbed curcumin was quantified using fluorescence microscopy images of cells. Briefly, SW480 cells were cultured up to $80 \%$ confluence on borosilicate sterile two-chambered cover glasses and treated with $50 \mu \mathrm{M}$ of plain curcumin and NEC samples. After 1,2,3, and $4 \mathrm{~h}$ of treatment, cells were washed thrice with DMEM without phenol red to remove unabsorbed curcumin. Fluorescence images of absorbed curcumin was captured on a Zeiss digital imaging workstation using an excitation filter of $485 \mathrm{~nm}$ and emission filters of $525-585 \mathrm{~nm}$, at 20x objective. Fifteen images were captured from each well from samples treated in two independent wells for the replications. The amount of absorbed curcumin was quantified using slide book software (Intelligent Imaging Innovations Inc, Denver, CO, USA), calculated as the mean of 12 selected images, and expressed as mean fluorescence intensity.

\subsection{Statistical analysis}

All experiments were carried in triplicate and the results are expressed as the average of three replications with three individual experiments. ANOVA was performed for activity studies 
and data were analyzed by Tukey's posttest analysis using Graph Pad Prism software version5.00.288. The cell culture results were considered significant as compared to control at $\mathrm{P}<0.05$.

\section{Results}

\subsection{Nano formulation and characterization}

In the present study, nanoencapsulated curcumin (NEC) was prepared for the first time at three different ratios, 70:30 (NEC-1), 50:50 (NEC-2), and 35:65 (NEC-3). The nanoencapsulated curcumin was prepared by adopting a modified desolvation method technique (Langer et al., 2003). Curcumin was dissolved in acetone, since the solubility of curcumin in water is very poor. When the acetone solution was added to aqueous protein solution, a fine dispersion of drug in polymeric organic phase was obtained. Three factors including primary stirring, homogenization speed, ratio of acetone:water and rate of addition are most important to obtain reproducible results. Fig. 1A shows the well dispersed clear solution of NECs whereas in plain curcumin $\left(4^{\text {th }}\right.$ vail) was settled at the bottom as an insoluble powder. Thus nanoencapsulation improved the solubility significantly for the effective delivery of curcumin in aqueous phase. In the present study, poorly water-soluble curcumin was trapped in the hydrophobic core of the micelle, while the hydrophilic shell enhances it solubility and micelle stabilization. The nanoencapsualtion of curcumin with whey protein makes unique formulation, which can offer enhanced solubility, stability, and bioavailability.

\subsection{Characterization of nanoencapsulated curcumin}

The size, PDI, and zeta $(\zeta)$ potential of nanoencapsulated curcumin are presented in Table S2. The NEC-1, NEC-2, and NEC-3 had an average diameter of 236.5 $\pm 8.8,212 \pm 3.4$, and 187 $\pm 11.4 \mathrm{~nm}$, respectively, as determined by DLS (Fig. 1B). The PDI of NEC-3 was relatively 
low $(<0.230 \pm 0.087)$, which indicates a high level of uniformity, whereas NEC-1 and NEC-2 exhibited moderate $(0.277 \pm 0.002)$ and $(0.261 \pm 0.031)$ PDI values, respectively. This may be due to their different composition of curcumin and whey protein.

\subsection{Drug loading, entrapment and stability of curcumin}

Quantitative ${ }^{1} \mathrm{H}$ NMR spectroscopy was used to determine the entrapment and stability of curcumin in nanoencapsulated samples (Fig. S1). The chemical shifts of all proton signals were assigned to the structure of curcumin. The integral area of each signal in the quantitative ${ }^{1} \mathrm{H}$ NMR spectrum is proportional to the number of nuclei that contribute to the signal. The peak areas of NMR signals from non-overlapping regions were chosen for accurate quantitative analysis. TSP- $\mathrm{d}_{4}$ in $\mathrm{D}_{2} \mathrm{O}$ was used as a quantitative reference. Fig. S1 shows the quantitative ${ }^{1} \mathrm{H}$ NMR spectra of the NEC and whey protein, along with the reference TSP- $\mathrm{d}_{4}$ signal from the external co-axial tube. This TSP- $\mathrm{d}_{4}$ signal appears at $-0.55 \mathrm{ppm}$. This difference in chemical shifts arises from the differences in the $2 \mathrm{H}$ lock frequency for $\mathrm{D}_{2} \mathrm{O}$ and DMSO- $\mathrm{d}_{6}$ solvents. The drug loading (curcumin content) in NEC-1, NEC-2, and NEC-3 was found to be $61.81 \pm 2.22 \%$, $41.39 \pm 1.34 \%$, and $33.72 \pm 0.66 \%$ and entrapment was $88.3 \pm 1.9,82.78 \pm 1.4 \%$ and $96.34 \pm$ 1.66 , respectively.

\subsection{Scanning electron microscopy of encapsulated curcumin}

Nanoencapsulated curcumin prepared by desolvation technique using whey protein as surfactant with different loading was found to be smooth, spherical shape particles (Fig. 2). The encapsulation of curcumin with whey protein at different ratios strongly affected nanoparticle morphology. The NEC-3 prepared using $65 \%$ whey protein had different sizes without holes and formed a very homogeneous population. The presence of pores in the surface of NEC-1 
nanoparticles could be attributed to the migration of curcumin towards the external aqueous phase during emulsification. It is well known that, sphere has the lowest interfacial area for a given volume of material. The spherical shaped nanoparticles resulted in nanospheres, wherein the curcumin was dispersed within the whey protein. Particle sizes of lyophilized nanoparticles under SEM images were observed to be relatively smaller in size than mean particle sizes of colloidal dispersion determined by photon correlation spectroscopy. This could be due to removal of moisture content present in the sample during sample preparation for SEM analysis and exposure of nanoparticles under vacuum while imaging under scanning electron microscope.

\subsection{In vitro release study}

In vitro release kinetics was analyzed to study the release rate of curcumin from NEC samples at neutral $\mathrm{pH}$. Our results indicated that encapsulation of curcumin with whey protein enhanced solubility, with slow release of curcumin in vitro (Fig. 2B). From the release profile, the self-assembled NEC can maintain its micellar architecture in neutral medium and the corresponding curcumin release rate is remarkably slow. For example at neutral pH, NEC-1, NEC-2, and NEC-3 released 42.24, 53.13, and 59.49\% of curcumin respectively at $24 \mathrm{~h}$, whereas at $48 \mathrm{~h},>70 \%$ release was observed. This sustained release of curcumin from NEC samples is expected to reduce the metabolic rate of curcumin release in vivo and will improve the bioavailability of curcumin.

\subsection{Influence of nanoencapsulation on cell proliferation of cancer cells}

Curcumin inhibits the proliferation of several organ-specific cancer cell lines, including colon cancer (Chidambara Murthy et al., 2013; Ling et al., 2014). To understand the effective concentration needed for the inhibition study, wide range from $50,25,10,5,2$, and $1 \mu \mathrm{M}$ was used for our initial cell viability assay. The encapsulated samples contains curcumin and whey 
protein with different concentrations, thus after applying the purity correction, the curcumin content was found to be $30.91 \mu \mathrm{M}, 20.70 \mu \mathrm{M}, 16.86 \mu \mathrm{M}$ in CLWP-1, CLWP-2 and CLWP-3 respectively. We have used colon (SW480), prostate (LNCaP) and pancreatic (Panc-28) cells to understand the sensitivity. Plain curcumin at $50 \mu \mathrm{M}$ exhibited $43 \%$ of SW480 cell proliferation after $48 \mathrm{~h}$ of treatment whereas NEC-1 $(30.91 \mu \mathrm{M})$, NEC-2 $(20.70 \mu \mathrm{M})$, and NEC-3 $(16.86 \mu \mathrm{M})$, showed $47 \%, 54.6 \%$, and $53.8 \%$ inhibition, respectively. Based on the equivalent concentration of curcumin, the inhibition was significant $(\mathrm{P}<0.05)$ in all three encapsulated samples. This corresponds to more than 3 fold enhanced activity with NEC-3, and >2 fold enhanced activity with NEC-1 and NEC-2 (Table S1) at all tested time points (Fig. 3). After 72h of treatment, plain curcumin $(25 \mu \mathrm{M})$ showed $33.8 \%$ inhibition while the encapsulated samples had 60.6 and $54.4 \%$ respectively for NEC-2 $(20.7 \mu \mathrm{M})$, and NEC-3 $(16.86 \mu \mathrm{M})$. In case of LNCaP cells, proliferation inhibition was $47.7 \%, 50.4 \%$ and $46.8 \%$ with treatment of $50 \mu \mathrm{M}$ equivalent concentration of NEC-1, NEC-2 and NEC-3, respectively after $24 \mathrm{~h}$. inhibition was enhanced by 3-5\% after $73 \mathrm{~h}$ in these concentrations (Fig. S2). Conversely, Panc-28 cells inhibition was similar to curcumin and $14.7 \%, 15.7 \%$ and $18.8 \%$ inhibition was observed after $24 \mathrm{~h}$ or treatment with NEC-1, NEC2 and NEC-3, respectively. At same incubation period curcumin at $50 \mu \mathrm{M}$ has shown inhibition of $20.6 \%$, suggesting the non-significant inhibition of cells by encapsulated cells (data not shown). Considering these results, we have conducted further experiments to understand the benefit at protein expression level using SW480 cells.

\subsection{Cytotoxicity of SW480 cells after treatment with nanoencapsulated curcumin.}

Our initial screening of proliferation inhibition was performed using three different (SW480, Panc-28 and LNCaP) cancer cell lines. The strong inhibition was found in colon cancer 
cells. Based on cell proliferation results, fluorescence imaging was used to confirm the induction of apoptosis in the curcumin-treated cells. Staining of treated cells with AO and PI showed the loss of cell permeability and nuclear damage (Fig. 4). Majority of control cells were stained with AO and PI was observed only outside the cells as bright spots, suggesting live SW480 cells. Similarly, none of the whey protein-treated cells were stained with PI indicating that cells are live. Conversely, treatment of NEC-1 showed very few cells and those were also stained with PI in the intracellular region, suggesting both dead and early apoptotic cells. Additionally, the green signal for AO was weaker with very few cells showing staining of the nucleus in NEC-1-treated cells (equivalent to $30.91 \mu \mathrm{M}$ ), suggesting fewer live cells in the area. Interestingly, cells treated with NEC-2 (equivalent to $20.70 \mu \mathrm{M}$ ) and NEC-3 (equivalent to $16.86 \mu \mathrm{M}$ ) completely stained with PI, showing strong induction of apoptosis. Staining of AO indicate that cells were with condensed nucleus and were of early apoptosis phase. Results were in agreement with cytotoxicity tests shown in Fig. 3. According to our previous research, curcumin didn't shown toxicity to normal colon $(112 \mathrm{CoN})$ cells treated up to $200 \mu \mathrm{g} / \mathrm{ml}$ (Chidambara Murthy et al., 2013). This provides us an impetus for considering further reduction of the curcumin dose specifically to targeted cancer cells. This ability of curcumin is also evident from its safety to animals and as well as human. Based on this, we were keen to understand the influence of encapsulated curcumin on major proteins acting on programmed cell death.

\subsection{Influence of nanoencapsulated curcumin on expression of apoptosis-related proteins in SW480 cells}

The significant elevation in the ratio of $\mathrm{Bax} / \mathrm{Bcl} 2$ in cells treated with encapsulated samples as compared plain curcumin was observed (Fig. 5). Additionally, expression of death- 
inducing protein (p53) was 0.7- and 2-fold higher in cells treated with NEC-2 (20.70 $\mu \mathrm{M})$ and NEC-3 $(16.86 \mu \mathrm{M})$, respectively as compared to plain curcumin. This corresponds to 3 and 20 fold higher activities with NEC-2 and NEC-3 at much lower concentration of curcumin, suggesting the benefit of nanoencapsulation. Expression of Bcl2-associated death promoter (BAD) also followed a similar trend, suggesting better efficacy of encapsulated curcumin samples. One of the key markers of intrinsic apoptosis, cytochrome-c concentration in the cytosol, was elevated by $11.5 \%$ in the nanoencapsulated sample (NEC-2), suggesting higher activity of curcumin.

\subsection{Measurement of curcumin absorption using fluorescence microscopy}

For cells treated with plain curcumin, the intracellular concentration was highest at $1 \mathrm{~h}$ (58.7 units) and further decreased (46.6 units) at $4 \mathrm{~h}$ (Fig. 6). For the nanoencapsulated samples, intracellular curcumin concentration did not change and NEC-1 (30.91 $\mu \mathrm{M})$ showed the highest concentration at $1 \mathrm{~h}$ with 60.7 units and 58.3 units at $4 \mathrm{~h}$. NEC-2 $(20.70 \mu \mathrm{M})$ showed an increase in the concentration from 46.8 units at $1 \mathrm{~h}$ to 66.7 units at $4 \mathrm{~h}$. In case of NEC-3 enhanced absorption of 22.5 and $20.2 \%$ was observed compared to curcumin after 3 and 4 h. This results clearly suggest that bioavailability of encapsulated curcumin was higher compared to plain curcumin.

\section{Discussion}

\subsection{Formulation of encapsulated curcumin, characterization and identification}

Curcumin is a promising natural compound for prevention of atherosclerosis and various cancers, including colon, skin, stomach, and breast cancers, as demonstrated by both clinical and pre-clinical studies (Aggarwal et al., 2003; Boyanapalli and Kong, 2015; Jayaprakasha et al., 
2005). Due to its poor stability, bioavailability and low absorption, we have tested nanoencapsulated curcumin for cell proliferation inhibition. Whey proteins are used widely in a variety of foods, primarily for their gelling and emulsification properties. $\beta$-lactoglobulin is the main component of whey protein and it has unique gelling and physicochemical properties suitable for food and pharmaceutical applications.

Curcumin has been demonstrated for increased stability and solubility in polar conditions upon complexion with BSA, $\beta$-lactoglobulin nanoparticle and soy protein isolate (Yang et al., 2013). The encapsulation of curcumin and proteins occurs mainly through hydrophobic interactions and hydrogen bonds (Zhang et al., 2014). The present study has demonstrated the use of whey protein for the first time at various levels to improve the biological activities of curcumin and stability for longer time periods. Encapsulation can protect the active ingredients and also enhance the biological benefits of active ingredients for optimum benefits. Various polymers such as $\mathrm{N}$-isopropylacrylamide, $\mathrm{N}$-vinyl-2-pyrrolidone, poly (ethylene glycol) monoacrylate (PEG-A) (Bisht et al., 2007) and biodegradable polymers including poly (lacticco-glycolide) have been used for nanoencapsulation of curcumin (Sahu et al., 2008a). Although these ingredients used for encapsulation are safe in animal experiments, their influences in longterm use and in humans are not fully understood. In this direction, the present study target to minimize the use of synthetic polymers to encapsulate the curcumin to understand the cell death markers in SW480 cells. Major reasons to use colon cancer are its high prevalence and success of turmeric compounds towards inhibition of proliferation and other associated symptoms in colon cancer reported by our research group and others (Aggarwal et al., 2003; Anand et al., 2007; Chidambara Murthy et al., 2013). 
The electrostatic interactions of the nanoparticles were also controlled by variation in their surface charges, which can be determined by measuring the zeta potential. The $\zeta$-potentials for NEC-1, NEC-2, and NEC-3 were $-13.1,-9.26$, and $-4.63 \mathrm{mV}$ at $\mathrm{pH} 3.0$, showing a roughly linear trend (Table S2) with respect to curcumin concentration. The low negative zeta potential is in the range known empirically as being non-disruptive to membranes and optimal for cellular uptake. As whey protein concentration increased from $30 \%$ to $65 \%$ in NEC-1, NEC-2, and NEC3, the negative zeta potential of each complex increased in a linear fashion.

It is clear from ${ }^{1} \mathrm{H}$ NMR spectra (Fig. S1), there are no degradation or structural changes that occurred during the formulation of nanoencapsulated curcumin. Quantitative NMR (qNMR) has been used to provide an unbiased view of sample composition, and, simultaneously, to quantify multiple compounds (Jayaprakasha and Patil, 2014). With qNMR, the quantitation of the compounds present in a complex sample can be performed in a single, rapid and nondestructive measurement. Thus, qNMR has become the method of choice for metabolome studies and quality control of complex natural samples such as foods, plants, herbal remedies, and biofluids (Jayaprakasha and Patil, 2016).

The NEC samples have spherical and smooth surfaces with very small holes (Fig. 2A). Many studies indicated that the nature and amount of surfactants and polymers will determine the characteristics of particle size and encapsulation efficiency (Barras et al., 2009; Dhawan et al., 2011). Curcumin is hydrophobic and can form a core within a shell of hydrophilic molecules (such as proteins) to form large nanocarriers. The particle size of nanocarriers depends on the ratios of polymer, surfactants, and drug molecule. 


\subsection{Role of nanoencapsulation on cell proliferation, cytotoxicity, expression of protein levels}

\section{and absorption}

Cytotoxicity results indicate significantly higher cell proliferation inhibition ability was observed in nanoencapsulated samples as compared to plain curcumin (Fig. 3). Among three different cell lines tested, colon (SW480) and prostate (LNCaP) cancer cells had higher sensitivity compared pancreatic (Panc-28) cells (Fig. S2). In our recent study, normal fibroblast cells (112CoN) and SW480 cells were used for inhibition of cell proliferation (Chidambara Murthy et al., 2013) at $200 \mu \mathrm{g} / \mathrm{ml}$ of curcumin. No significant inhibition was observed for normal cells. Thus, normal cells were not used in the present study.

Benefit of encapsulation in induction of apoptosis was also evident from staining of treated cells with $\mathrm{AO}$ and PI, which confirms the patters on cell death (Fig. 4). This could be due to either reduction in particle size or encapsulation of curcumin with whey protein. Encapsulation has resulted in sustain release of compound, which helped to act for longer time period. Several studies on encapsulation of curcumin by polymers (biodegradable or nondegradable), liposomes, and other natural ingredients have shown that encapsulation enhances the cytotoxicity of curcumin on cancer cell lines (Bisht et al., 2007; Li et al., 2005). However, use of synthetic polymers will have its own disadvantages with respect to its effect on tumor or healthy cells (DeMerlis and Schoneker, 2003). Such adverse effects can be reduced by using natural, safe polymers such as whey protein.

Unlike synthetic molecules, curcumin acts on multiple pathways that interact with various aspects of cell life which includes, free radical scavenging, immune modulation in normal cells, and induction programmed cell death and inhibition of inflammation in cancer cells 
(Jayaprakasha et al., 2005; Kunnumakkara et al., 2008). Thus we were also interested in understanding the extent of influence of encapsulated curcumin on key markers related induction of programmed cell death in cells. Results clearly suggest the benefit of NEC over plain curcumin, based on the elevation of pro-apoptotic proteins (Bax, p53 and BAD) and depletion in expression of anti-apoptotic (bcl2) protein (Fig. 5). These suggest that apart from increased proliferation activity, there is also enhanced mode of apoptosis induction, which confirms the benefit of encapsulation process. Bioavailability of curcumin is one of the major hurdles in its utilization for various health benefits (McClements et al., 2015). Among different approaches to increase the bioavailability, co-administration with glucuronidation inhibitors, formulation to liposomes, nanoparticles, encapsulation are some of the techniques reported. Since our study involve use of both nano sized curcumin and encapsulated samples, thus we were keen to understand the extent of bioavailability. Based on the fluorescent nature of curcumin, fluorescence imaging was used to trace the amount of curcumin absorbed by cells to understand the extent of bioavailability (Bisht et al., 2007; Sahu et al., 2008b). The fluorescence intensity was decreased after $4 \mathrm{~h}$ in nanoencapsulated samples treated cells. Fluorescence of control cells and whey protein-treated cells were measured and subtracted to account for actual curcumin content in the cell. These results further support the idea that the encapsulated form shows better absorption of curcumin and slow release, which is one of the most-desired properties for better biological activity.

Existing in vitro, in vivo, and clinical research indicates that curcumin is one of the most beneficial bioactive molecules of dietary origin used for prevention of various diseases including cancer (Kocher et al., 2015). Curcumin can inhibit inflammation, which is a major culprit in the development and progression of cancer (Zhang et al., 2015). Unlike most of the effective drug 
molecules, curcumin is abundantly available in nature and easy to use (Chen et al., 2016).

Curcumin also effectively targets cancer cells without being toxic to normal cells, killing cancer cells by inducing cytotoxicity through established biochemical pathways, including major events like intrinsic/extrinsic apoptosis, cell cycle arrest, anti-angiogenesis, inhibition of inflammation, and suppression of anti-apoptotic proteins (Kumar et al., 2016). The major advantage of curcumin as a therapeutic agent is its safety; consumption of more than $6 \mathrm{~g} /$ day for three months did not cause any abnormalities, as observed in a Taiwan curcumin chemoprevention trial group (Chueh et al., 2003). Another clinical study shown that curcumin is safe up to $12 \mathrm{~g} /$ day administered orally (Anand et al., 2007). Considering the benefit of enhanced bioavailability and efficacy of curcumin in prevention of cancer, results of the present study provide better opportunity for clinical utilization. Based on the safety of excipients used to enhance the bioavailability and nanosize particles of curcumin, further studies can be undertaken for validation of data with large scale production and evaluation of pharmacokinetic information using in vivo system.

In conclusions, nanoencapsulated curcumin was prepared with small amount of organic solvents to enhance the water solubility and enhance the delivery efficacy of curcumin. The mean diameter of NEC was found to be less than $240 \mathrm{~nm}$ with excellent PDI, narrow size distributions, and no agglomeration. The encapsulated curcumin samples enhanced cytotoxicity more than 3 fold with NEC-3, and > 2 fold enhanced activity with NEC-1 and NEC-2 at all tested time points. Additionally, increased content of major proteins representing the activation of programmed cell death by NEC suggest the advantage of encapsulation with natural ingredients. These results indicate that it is possible to achieve higher bioavailability and bio-efficacy using safe and economical encapsulating media. The current results provide an impetus for considering 
whey protein-based nanoparticles for scaling up and safety studies for potential human applications.

\section{Acknowledgements}

This research is based upon work supported by the USDA-NIFA \#2010-34402-20875

“Designing Foods for Health" through the VFIC and State Funding-2013-121277 Vegetable \& Fruit Improvement Center-TX State Appropriation. Authors also thank Dr. Bisrat Yordanos, TAMU Materials Characterization Facility for SEM analysis.

\section{Figure captions}

Fig. 1 (A). Typical nanoencapsulated curcumin and plain curcumin dispersed in buffer. (B). Logarithmic size distribution (diameter) of different encapsulated curcumin samples at three different ratios. The size distribution of the particles were analyzed by Zetasizer nano ZS.

Fig. 2. (A). Typical scanning electron microscope (SEM) images of nanoencapsulated curcumin (NEC) with whey protein samples prepared by desolvation method, (B). Release rate (\%) of NEC samples. Known amounts of samples were dispersed in acidic buffer and kept on a shaker for 48 h. At specific time points, $500 \mu l$ samples were analyzed by HPLC. NEC-1 [nanoencapsulated curcumin-1: (70:30) 61.81\% curcumin)], NEC-2 [nanoencapsulated curcumin (50:50) - 41.39\% curcumin)] and NEC-3 [nanoencapsulated curcumin (35:65) -33.72\% curcumin)]. 
Fig. 3. Proliferation inhibition of SW-480 cells by curcumin and nanoencapsulated samples as measured by MTT assay. Data are expressed as mean \pm S.D. for triplicate experiments $(n=8-9)$. Values were significant compared to control at $\mathrm{P}<0.05$ for all the concentrations and time points. The curcumin content in NEC-1, NEC-2 and NEC-3 was $30.91 \mu \mathrm{M} ; 20.70 \mu \mathrm{M}, 16.86 \mu \mathrm{M}$ respectively is equivalent to $50 \mu \mathrm{M}$ of nanoencapsulated curcumin (NEC).

Fig. 4. Fluorescence images of SW480 cells showing cytotoxicity caused by nanoencapsulated curcumin (NEC) at $50 \mu \mathrm{M}$ (corresponding to $30.91 \mu \mathrm{M} ; 20.70 \mu \mathrm{M}, 16.86 \mu \mathrm{M}$ of curcumin in NEC-1, NEC-2 and NEC-3, respectively) for $24 \mathrm{~h}$. Cells were stained with acridine orange (green signal, left panels) and propidium iodide (red signals, right panels) at $5 \mu \mathrm{M}$ each and incubated for $15 \mathrm{~min}$ at $37^{\circ} \mathrm{C}$ in $85 \pm 5 \% \mathrm{RH}$. Fluorescence images of cells were captured using a Zeiss Digital Imaging Workstation. Each treatment was done on three independent slides and a representative image for the three identical experiments is presented.

Fig. 5. (A). Influence of plain and nanoencapsulated curcumin (NEC) samples on expression of apoptosis-related proteins in SW480 cells; (B). Relative abundance of major proteins. Proteins from treated cells were separated on $12 \%$ SDS-PAGE and transferred to nitrocellulose membrane. Immunoblotting using $\beta$ - actin, $\mathrm{p} 53, \mathrm{Bax}, \mathrm{Bcl}_{2}$, cytochrome-c, and $\mathrm{BAD}$ antibodies was performed as described in Methods. The curcumin content in NEC-1, NEC-2 and NEC-3 was $30.91 \mu \mathrm{M} ; 20.70 \mu \mathrm{M}, 16.86 \mu \mathrm{M}$, respectively, which is equivalent to $50 \mu \mathrm{M}$ of NEC samples.

Fig. 6. Absorption of curcumin was measured by fluorescence imaging. Briefly, the SW480 cells were treated with nanoencapsulated curcumin (NEC) samples and plain curcumin at $50 \mu \mathrm{M}$. 
After incubation for 1, 2, 3, and $4 \mathrm{~h}$, cells were washed to remove unabsorbed curcumin and a fluorescence image of the absorbed curcumin was captured using a Zeiss digital imaging workstation as explained in Methods. The curcumin content in NEC-1, NEC-2 and NEC-3 was $30.91 \mu \mathrm{M} ; 20.70 \mu \mathrm{M}, 16.86 \mu \mathrm{M}$, respectively, which is equivalent to $50 \mu \mathrm{M}$ of nanoencapsulated curcumin. 


\section{References}

Aggarwal, B.B., Kumar, A., Bharti, A.C., 2003. Anticancer potential of curcumin: preclinical and clinical studies. Anticancer Res. 23, 363 - 398.

Anand, P., Kunnumakkara, A.B., Newman, R.A., Aggarwal, B.B., 2007. Bioavailability of Curcumin: Problems and Promises. Mol. Pharm. 4, 807-818.

Barras, A., Mezzetti, A., Richard, A., Lazzaroni, S., Roux, S., Melnyk, P., Betbeder, D., Monfilliette-Dupont, N., 2009. Formulation and characterization of polyphenol-loaded lipid nanocapsules. Int. J. Pharm. 379, 270-277.

Bisht, S., Feldmann, G., Soni, S., Ravi, R., Karikar, C., Maitra, A., Maitra, A., 2007. Polymeric nanoparticle-encapsulated curcumin ("nanocurcumin"): a novel strategy for human cancer therapy. J. Nanobiotechnol. 5, 1-18.

Boyanapalli, S.S., Kong, A.-N.T., 2015. "Curcumin, the King of Spices”: Epigenetic Regulatory Mechanisms in the Prevention of Cancer, Neurological, and Inflammatory Diseases. Curr. Pharm. Rep. 1, 129-139.

Chen, J., He, Z.-M., Wang, F.-L., Zhang, Z.-S., Liu, X.-Z., Zhai, D.-D., Chen, W.-D., 2016. Curcumin and its promise as an anticancer drug: An analysis of its anticancer and antifungal effects in cancer and associated complications from invasive fungal infections. Eur. J. Pharmacol. 772, 33-42.

Chidambara Murthy, K.N., Jayaprakasha, G.K., Patil, B.S., 2013. Citrus limonoids and curcumin additively inhibit human colon cancer cells. Food Funct. 4, 803-810.

Chueh, S.C.J., Lai, M.K., Liu, I.S., Teng, F.C., Chen, J., 2003. Curcumin enhances the immunosuppressive activity of cyclosporine in rat cardiac allografts and in mixed lymphocyte reactions. Transplant. Proc. 35, 1603-1605. 
DeMerlis, C., Schoneker, D., 2003. Review of the oral toxicity of polyvinyl alcohol (PVA). Food Chem. Toxicol. 41, 319-326.

Dhawan, S., Kapil, R., Singh, B., 2011. Formulation development and systematic optimization of solid lipid nanoparticles of quercetin for improved brain delivery. J. Pharm. Pharmacol. 63, $342-351$.

Elzoghby, A.O., Samy, W.M., Elgindy, N.A., 2012. Albumin-based nanoparticles as potential controlled release drug delivery systems. J. Control. Release 157, 168-182.

Jayaprakasha, G.K., Jagan Mohan Rao, L., Sakariah, K.K., 2005. Chemistry and biological activities of Curcuma longa. Trends Food Sci. Tech. 16, 533-548.

Jayaprakasha, G.K., Nagana Gowda, G.A., Marquez, S., Patil, B.S., 2013. Rapid separation and quantitation of curcuminoids combining pseudo two-dimensional liquid flash chromatography and NMR spectroscopy. J. Chromatogr. B 937, 25-32.

Jayaprakasha, G.K., Patil, B.S., 2014. Quantification of health-promoting compounds by quantitative ${ }^{1}$ HNMR spectroscopy. ACS Symp. Ser. 1185, 289-302.

Jayaprakasha, G.K., Patil, B.S., 2016. A metabolomics approach to identify and quantify the phytochemicals in watermelons by quantitative ${ }^{1}$ HNMR. Talanta 153, 268-277.

Kocher, A., Schiborr, C., Behnam, D., Frank, J., 2015. The oral bioavailability of curcuminoids in healthy humans is markedly enhanced by micellar solubilisation but not further improved by simultaneous ingestion of sesamin, ferulic acid, naringenin and xanthohumol. J. Funct. Foods 14, 183-191.

Kumar, G., Mittal, S., Sak, K., Tuli, H.S., 2016. Molecular mechanisms underlying chemopreventive potential of curcumin: Current challenges and future perspectives. Life Sci. $148,313-328$. 
Kunnumakkara, A.B., Anand, P., Aggarwal, B.B., 2008. Curcumin inhibits proliferation, invasion, angiogenesis and metastasis of different cancers through interaction with multiple cell signaling proteins. Cancer Lett. 269, 199-225.

Langer, K., Balthasar, S., Vogel, V., Dinauer, N., Von Briesen, H., Schubert, D., 2003. Optimization of the preparation process for human serum albumin (HSA) nanoparticles. Int. J. Pharm. 257, 169-180.

Li, L., Braiteh, F.S., Kurzrock, R., 2005. Liposome-encapsulated curcumin. Cancer 104, 13221331.

Ling, X., Gandhi, N., Jiao, B., Chandra, D., Li, F., 2014. Synergistic effect of curcumin on FL118 efficacy in colon cancer. Cancer Res. 74, 802-802.

Marczylo, T., Verschoyle, R., Cooke, D., Morazzoni, P., Steward, W., Gescher, A., 2007. Comparison of systemic availability of curcumin with that of curcumin formulated with phosphatidylcholine. Cancer Chemotherapy and Pharmacology 60, 171-177.

McClements, D.J., Li, F., Xiao, H., 2015. The nutraceutical bioavailability classification scheme: classifying nutraceuticals according to factors limiting their oral bioavailability. Annu. Rev. Food Sci. Technol. 6, 299-327.

Murthy, K.N.C., Jayaprakasha, G.K., Kumar, V., Rathore, K.S., Patil, B.S., 2011. Citrus limonin and its glucoside inhibit colon adenocarcinoma cell proliferation through apoptosis. J. Agric. Food Chem. 59, 2314-2323.

Murthy, K.N.C., Jayaprakasha, G.K., Patil, B.S., 2012. The natural alkaloid berberine targets multiple pathways to induce cell death in cultured human colon cancer cells. Eur. J. Pharmacol. 688, 14-21. 
Ndong, N.G.M.A., Granet, R., Mbakidi, J.P., Brégier, F., Léger, D.Y., Fidanzi-Dugas, C., Lequart, V., Joly, N., Liagre, B., Chaleix, V., Sol, V., 2016. Development of curcumincyclodextrin/cellulose nanocrystals complexes: New anticancer drug delivery systems. Bioorg. Med. Chem. Lett. 26, 941-945.

Patil, J.R., Jayaprakasha, G., Chidambara Murthy, K., Tichy, S.E., Chetti, M.B., Patil, B.S., 2009. Apoptosis-mediated proliferation inhibition of human colon cancer cells by volatile principles of Citrus aurantifolia. Food Chem. 114, 1351-1358.

Sahu, A., Bora, U., Kasoju, N., Goswami, P., 2008a. Synthesis of novel biodegradable and selfassembling methoxy poly(ethylene glycol)-palmitate nanocarrier for curcumin delivery to cancer cells. Acta Biomaterialia 4, 1752-1761.

Sahu, A., Kasoju, N., Bora, U., 2008b. Fluorescence study of the curcumin- casein micelle complexation and its application as a drug nanocarrier to cancer cells. Biomacromolecules 9, 2905-2912.

Shehzad, A., Wahid, F., Lee, Y.S., 2010. Curcumin in Cancer Chemoprevention: Molecular Targets, Pharmacokinetics, Bioavailability, and Clinical Trials. Archiv der Pharmazie 343, 489-499.

Shoba, G., Joy, D., Joseph, T., Majeed, M., Rajendran, R., Srinivas, P.S.S.R., 1998. Influence of Piperine on the Pharmacokinetics of Curcumin in Animals and Human Volunteers. Planta Med 64, 353,356.

Yallapu, M.M., Nagesh, P.K.B., Jaggi, M., Chauhan, S.C., 2015. Therapeutic Applications of Curcumin Nanoformulations. AAPS J. 17, 1341-1356. 
Yang, M., Wu, Y., Li, J., Zhou, H., Wang, X., 2013. Binding of curcumin with bovine serum albumin in the presence of $\mathbf{t}$-carrageenan and implications on the stability and antioxidant activity of curcumin. J. Agric. Food Chem. 61, 7150-7155.

Zhang, L., Qi, Z., Huang, Q., Zeng, K., Sun, X., Li, J., Liu, Y.-N., 2014. Imprinted-like biopolymeric micelles as efficient nanovehicles for curcumin delivery. Colloids Surf., B $123,15-22$.

Zhang, X., Wang, R., Chen, G., Dejean, L., Chen, Q.-H., 2015. The Effects of Curcumin-based Compounds on Proliferation and Cell Death in Cervical Cancer Cells. Anticancer Res. 35, 5293-5298. 
(A). Aqueous suspensions of nanoencapsulated curcumin samples and plain curcumin

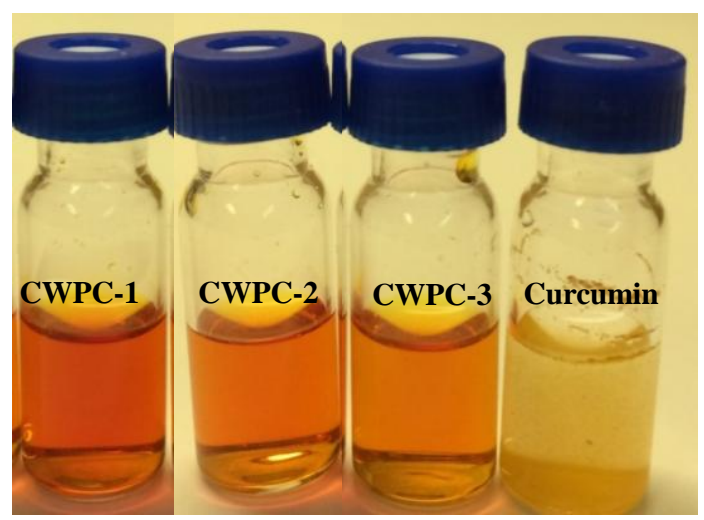

(B). Size Distribution by Intensity
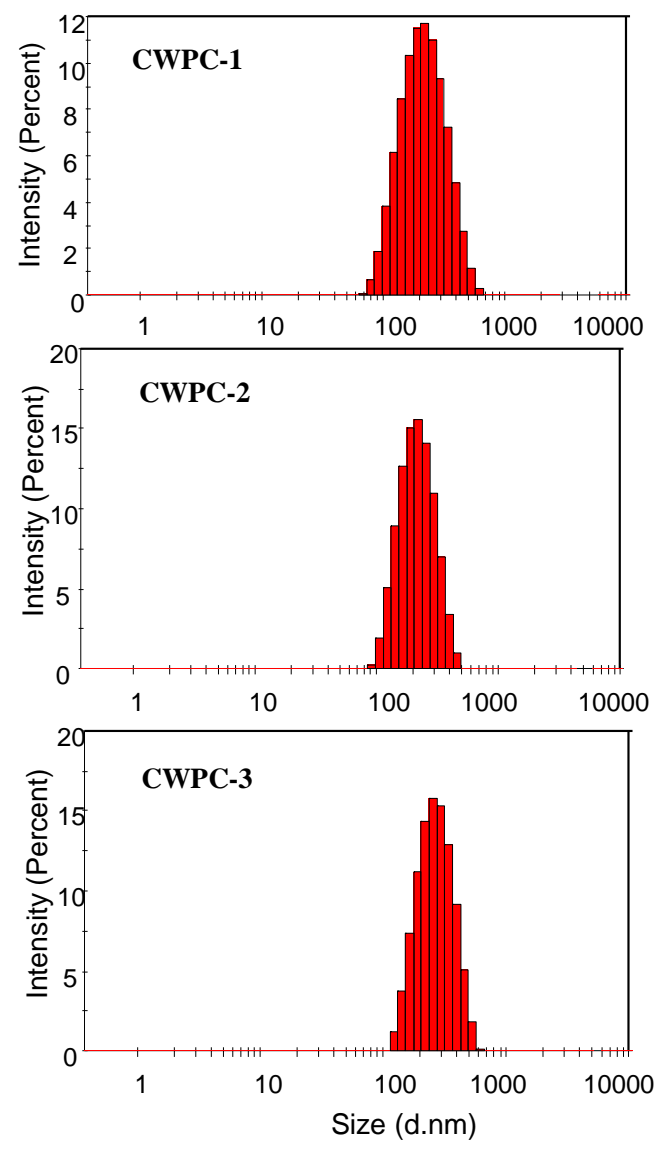

Fig. 1 (A). Typical nanoencapsulated curcumin and plain curcumin dispersed in buffer. (B). Logarithmic size distribution (diameter) of different encapsulated curcumin samples at three different ratios. The size distribution of the particles were analyzed by Zetasizer nano ZS. 

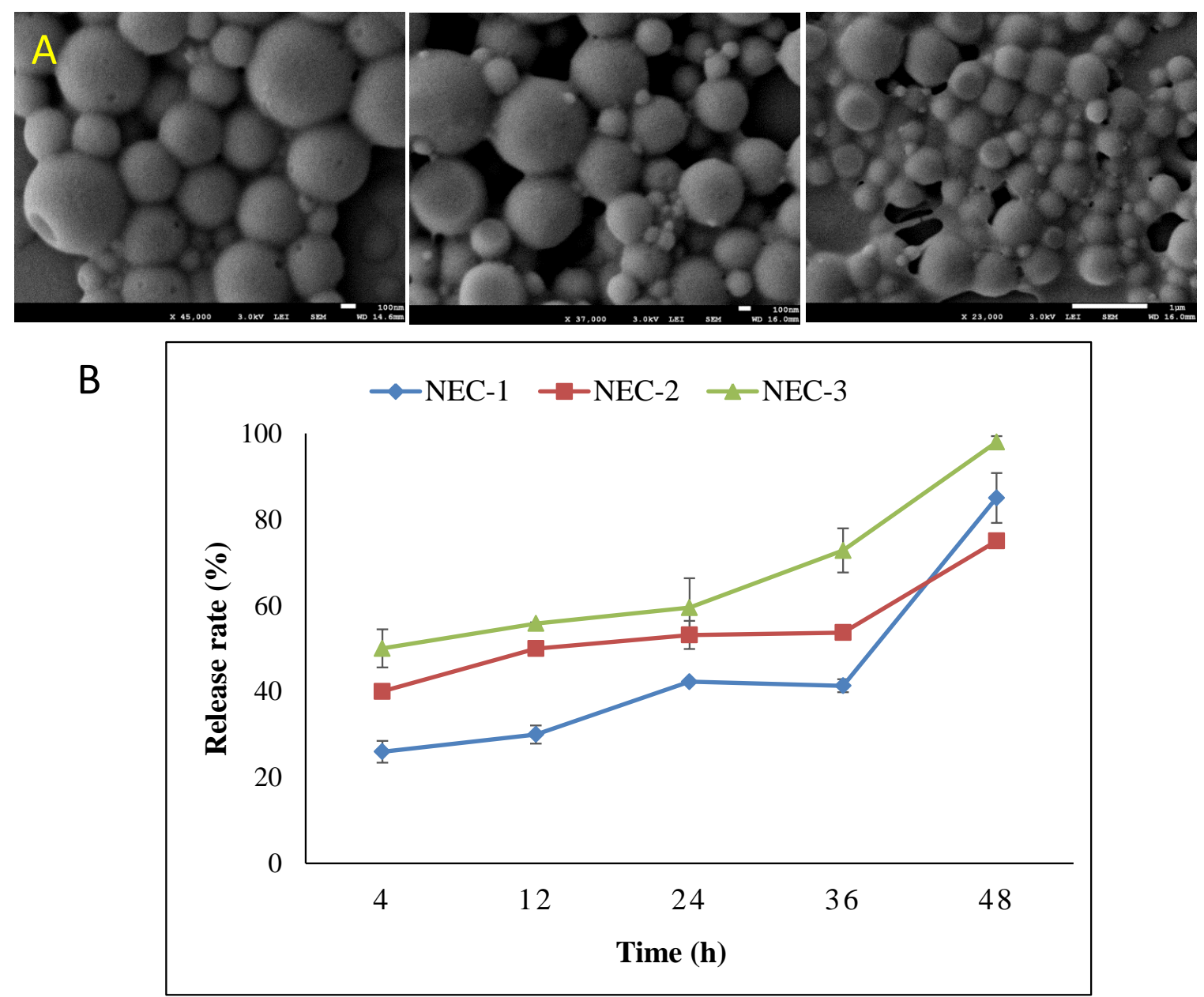

Fig 2. (A). Typical scanning electron microscope (SEM) images of nanoencapsulated curcumin (NEC) with whey protein samples prepared by desolvation method, (B). Release rate (\%) of NEC samples. Known amounts of samples were dispersed in acidic buffer and kept on a shaker for $48 \mathrm{~h}$. At specific time points, $500 \mu \mathrm{l}$ samples were analyzed by HPLC. NEC-1 [nanoencapsulated curcumin-1: (70:30) 61.81\% curcumin)], NEC-2 [nanoencapsulated curcumin (50:50) - 41.39\% curcumin)] and NEC-3 [nanoencapsulated curcumin (35:65) -33.72\% curcumin)]. 


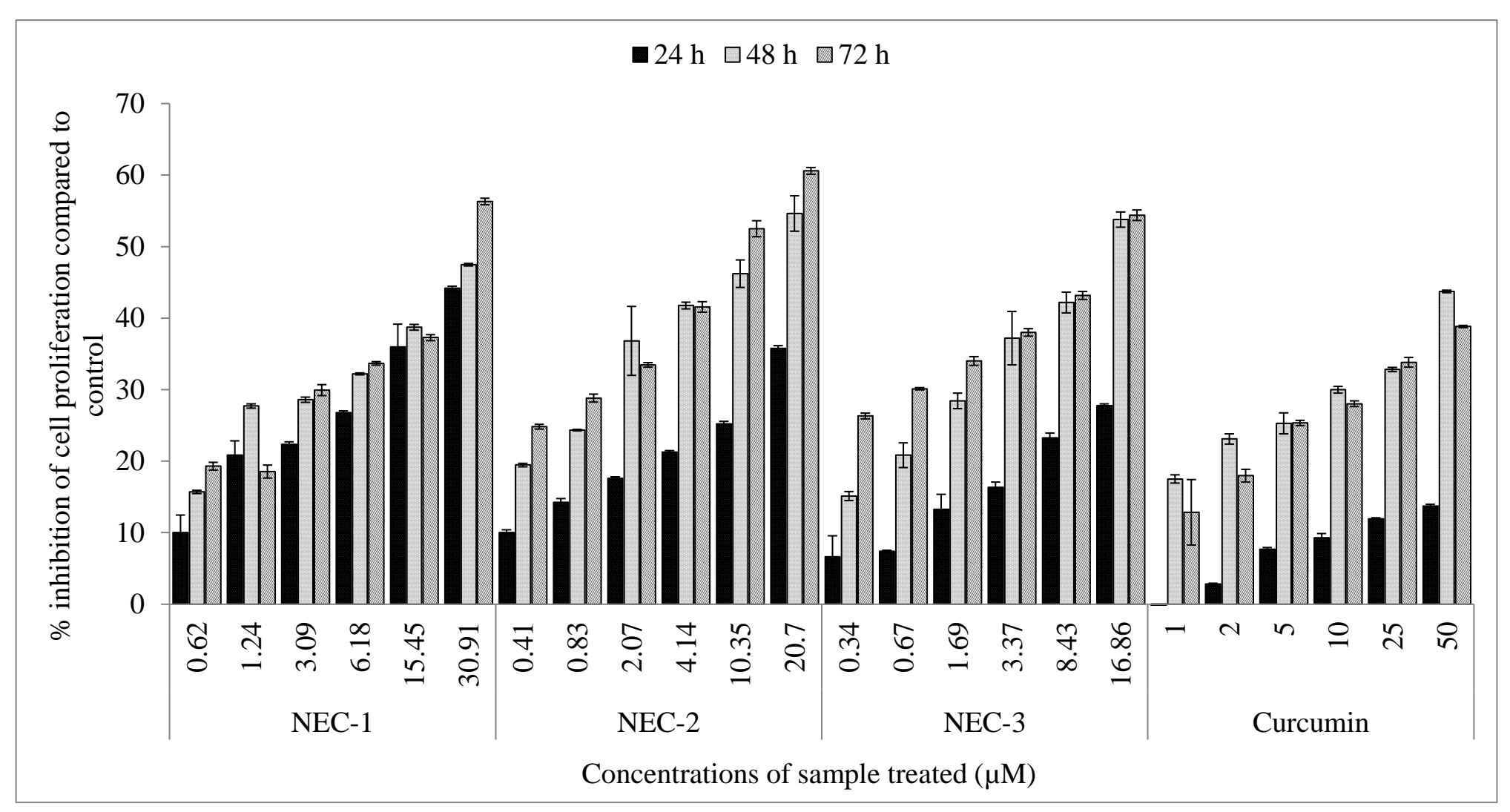

Fig 3. Proliferation inhibition of SW-480 cells by curcumin and nanoencapsulated samples as measured by MTT assay. Data are expressed as mean \pm S.D. for triplicate experiments $(n=8-9)$. Values were significant compared to control at $\mathrm{P}<0.05$ for all the concentrations and time points. The curcumin content in NEC-1, NEC-2 and NEC-3 was $30.91 \mu \mathrm{M} ; 20.70 \mu \mathrm{M}, 16.86 \mu \mathrm{M}$ respectively is equivalent to $50 \mu \mathrm{M}$ of nanoencapsulated curcumin (NEC). 


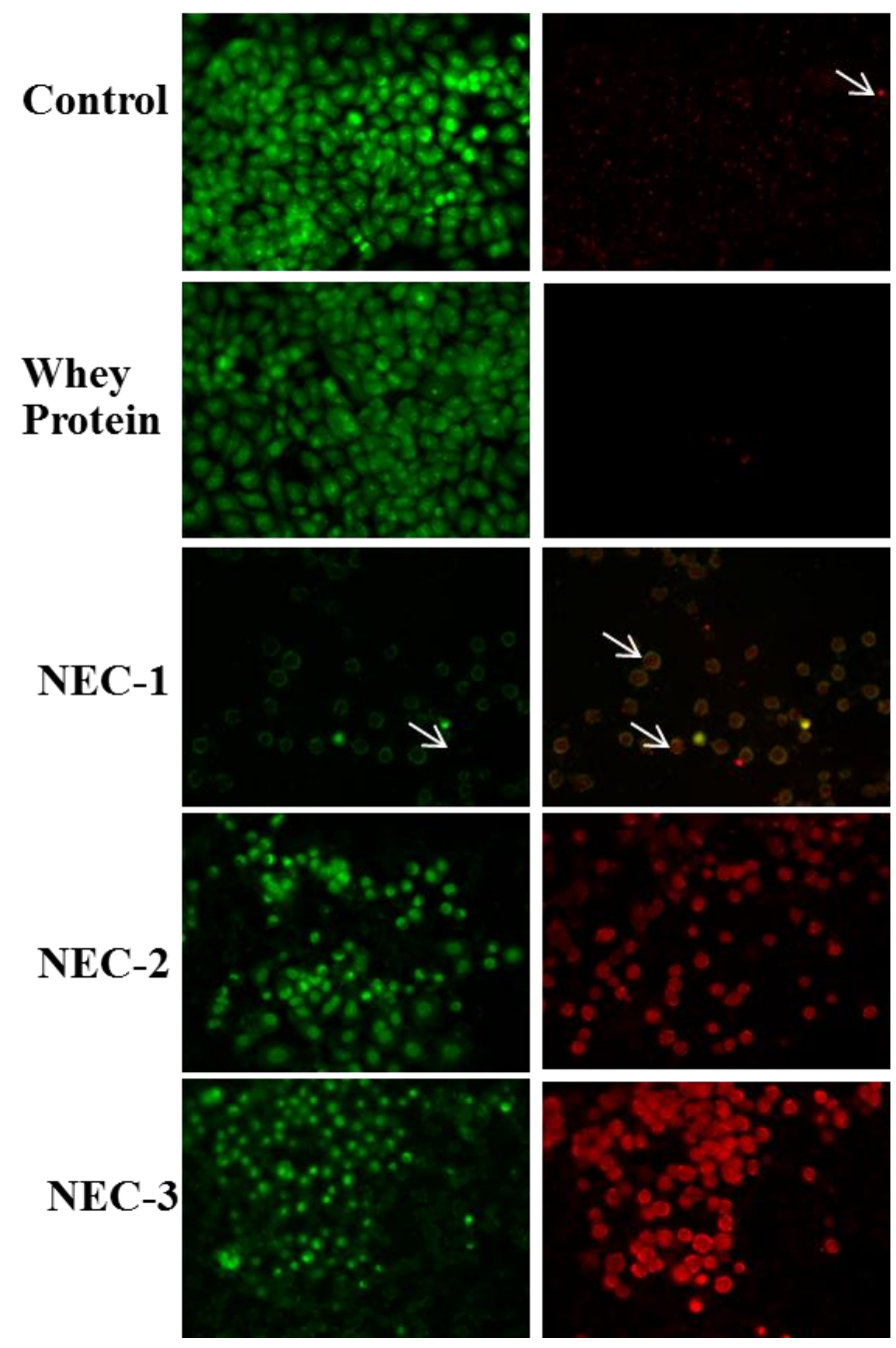

Fig 4. Fluorescence images of SW480 cells showing cytotoxicity caused by nanoencapsulated curcumin (NEC) at $50 \mu \mathrm{M}$ (corresponding to $30.91 \mu \mathrm{M} ; 20.70 \mu \mathrm{M}, 16.86 \mu \mathrm{M}$ of curcumin in NEC-1, NEC-2 and NEC-3, respectively) for $24 \mathrm{~h}$. Cells were stained with acridine orange (green signal, left panels) and propidium iodide (red signals, right panels) at $5 \mu \mathrm{M}$ each and incubated for $15 \mathrm{~min}$ at $37^{\circ} \mathrm{C}$ in $85 \pm 5 \% \mathrm{RH}$. Fluorescence images of cells were captured using a Zeiss Digital Imaging Workstation. Each treatment was done on three independent slides and a representative image for the three identical experiments is presented. 


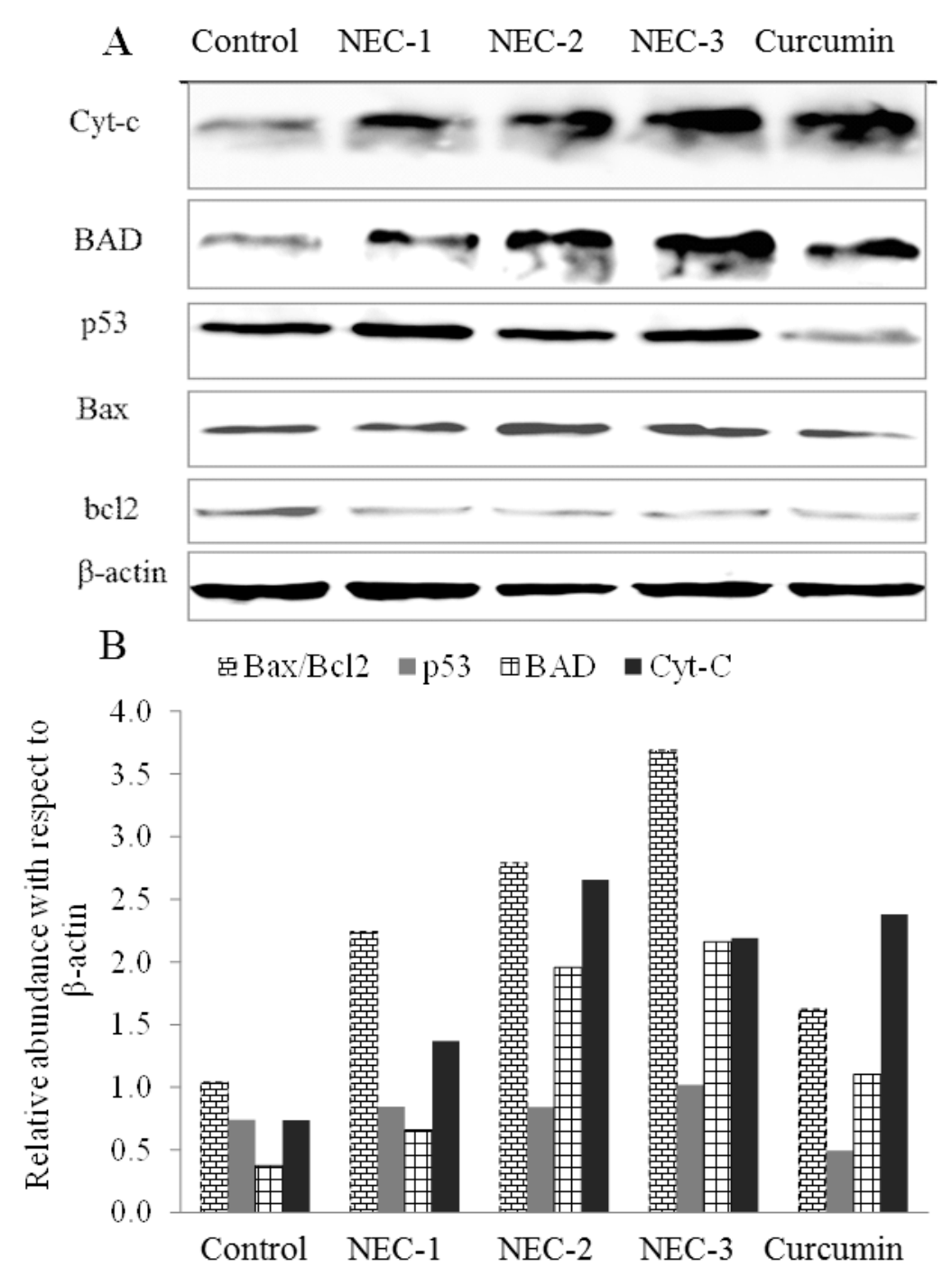

Fig 5. (A). Influence of plain and nanoencapsulated curcumin (NEC) samples on expression of apoptosis-related proteins in SW480 cells; (B). Relative abundance of major proteins. Proteins from treated cells were separated on 12\% SDS-PAGE and transferred to nitrocellulose membrane. Immunoblotting using $\beta$ - actin, p53, $\mathrm{Bax}, \mathrm{Bcl}_{2}$, cytochrome-c, and BAD antibodies was performed as described in Methods. The curcumin content in NEC-1, NEC-2 and NEC-3 was $30.91 \mu \mathrm{M} ; 20.70 \mu \mathrm{M}, 16.86 \mu \mathrm{M}$, respectively, which is equivalent to $50 \mu \mathrm{M}$ of NEC samples. 

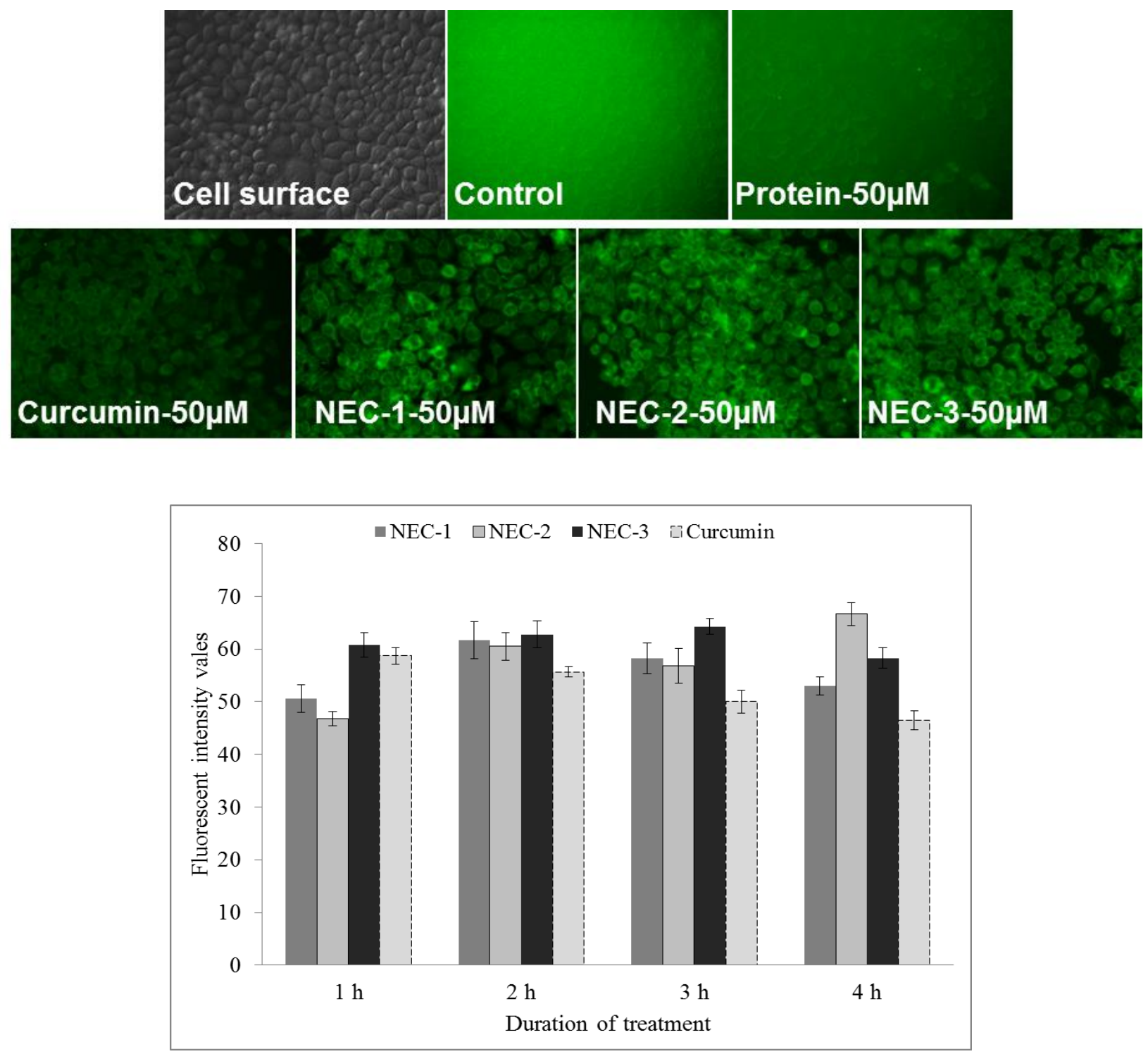

Fig 6. Absorption of curcumin was measured by fluorescence imaging. Briefly, the SW480 cells were treated with nanoencapsulated curcumin (NEC) samples and plain curcumin at $50 \mu \mathrm{M}$. After incubation for 1, 2, 3, and $4 \mathrm{~h}$, cells were washed to remove unabsorbed curcumin and a fluorescence image of the absorbed curcumin was captured using a Zeiss digital imaging workstation as explained in Methods. The curcumin content in NEC-1, NEC-2 and NEC-3 was $30.91 \mu \mathrm{M} ; 20.70 \mu \mathrm{M}, 16.86 \mu \mathrm{M}$, respectively, which is equivalent to $50 \mu \mathrm{M}$ of nanoencapsulated curcumin. 